\title{
TPX Superconducting Cable-in-Conduit 1995 Design and Development Progress
} RECEIVED

\author{
nor 171995 \\ OSAI
}

\author{
J. P. Zbasnik, N. N. Martovetsky, S. M. Hibbs, \\ J. H. Schultz, R. D. Pillsbury Jr., J. C. Citrolo
}

This paper was prepared for submittal to the

Proceedings of the 16th IEEE/NPSS Symposium on Fusion Engineering

Champaign, Illinois

September 30 - October 5, 1995

September 29, 1995

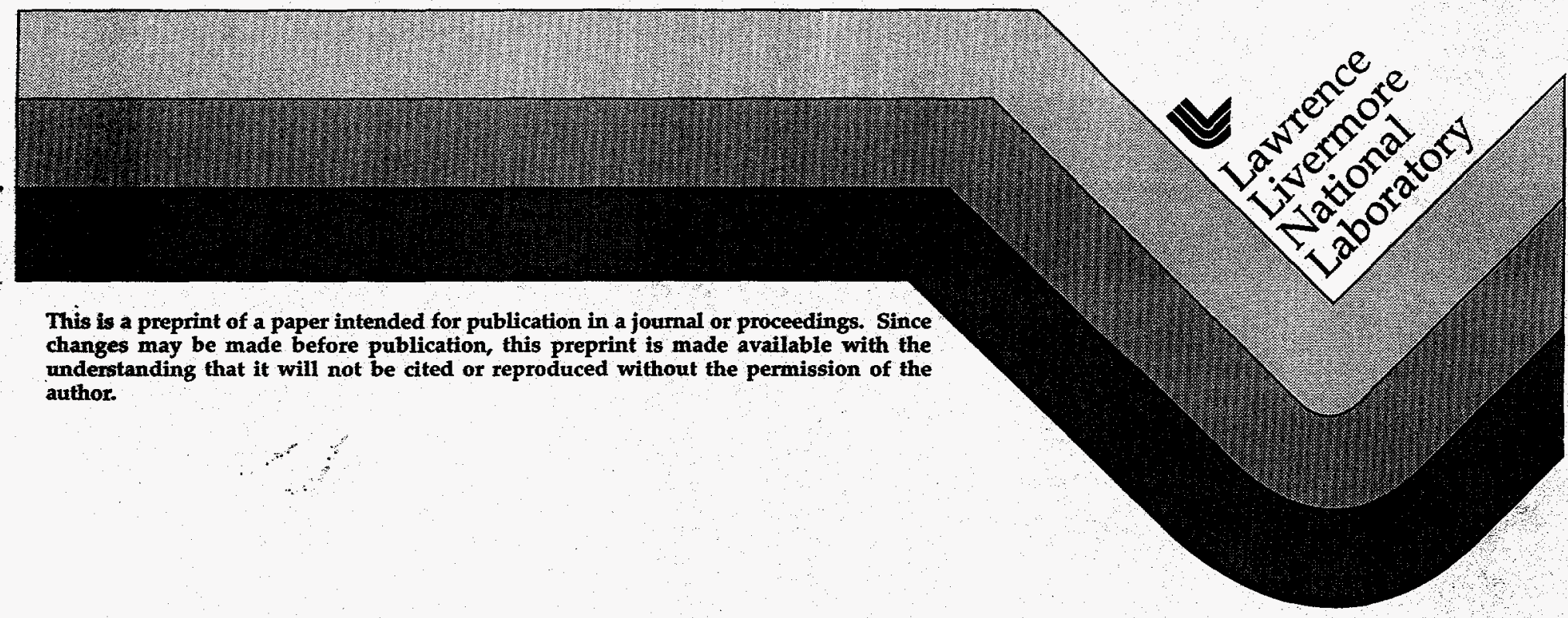




\section{DISCLAIMER}

This report was prepared as an account of work sponsored by an agency of the United States Government. Neither the United States Government nor any agency thereof, nor any of their employees, make any warranty, express or implied, or assumes any legal liability or responsibility for the accuracy, completeness, or usefulness of any information, apparatus, product, or process disclosed, or represents that its use would not infringe privately owned rights. Reference herein to any specific commercial product, process, or service by trade name, trademark, manufacturer, or otherwise does not necessarily constitute or imply its endorsement, recommendation, or favoring by the United States Government or any agency thereof. The views and opinions of authors expressed herein do not necessarily state or reflect those of the United States Government or any agency thereof. 


\section{DISCLAIMER}

Portions of this document may be illegible electronic image products. Images are produced from the best available original document. 


\title{
TPX Superconducting Cable-In-Conduit 1995 Design and Development Progress
}

\author{
J. P. Zbasnik, N. N. Martovetsky, S. M. Hibbs \\ Lawrence Livermore National Laboratory, Livermore, CA 94550 \\ J. H. Schultz, R. D. Pillsbury, Jr. \\ Massachusetts Institute of Technology, Plasma Fusion Center, Cambridge, MA 02139 \\ J. C. Citrolo \\ Princeton Plasma Physics Laboratory, Princeton, NJ 08543
}

\begin{abstract}
A unique feature of the magnet system for the Tokamak Physics Experiment (TPX) is that all the magnets are superconducting. With the exception of the outer poloidal coils, the magnet system uses $\mathrm{Nb}_{3} \mathrm{Sn}$ cable-in-conduit conductor; the outer poloidal coils use $\mathrm{Nb}$-Ti cable-in-conduit conductor. We describe the current TPX conductor design and present a progress report on the conductor development. Our strand development contracts have resulted in demonstrating that at least two vendors can produce $\mathrm{Nb}_{3} \mathrm{Sn}$ strand which meets the TPX specification. Subcable testing gives confidence that the TPX conductor will satisfy the magnet operational requirements. Fabrication of full-size conductors is underway and tests on these will give verification that the TPX conductor meets the operational requirements. Our industrial cabling and sheathing contract to produce demonstration conductor using copper strands is exploring a production technique that differs from the conventional tube mill approach.
\end{abstract}

\section{INTRODUCTION}

The Tokamak Physics Experiment (TPX), an advanced steady state plasma physics machine to be built at the Princeton Plasma Physics Laboratory, was to be the world's first Tokamak with a complete set of superconducting main coils. An overview of the TPX Magnet System is presented by G. A. Deis, et al. [1] and the Poloidal Field (PF) system is discussed by $\mathrm{H}$. Calvin, et al. [2] elsewhere in this conference. All of the TPX coils will use Cable-in-Conduit-Conductors (CICC) cooled with flowing supercritical helium. The Toroidal Field (TF) coils will require a $\mathrm{Nb}_{3} \mathrm{Sn}$ superconductor with a copper to noncopper ratio of $2.5: 1$, the Central Solenoid (CS) and PF 5 will use a $\mathrm{Nb}_{3} \mathrm{Sn}$ superconductor with a copper to noncopper ratio of 3.5:1, and PF 6 and PF 7 will use $\mathrm{Nb}-\mathrm{Ti}$ superconductor with a copper to superconductor ratio of 2.5:1. The conduit material for the $\mathrm{Nb}_{3} \mathrm{Sn}$ conductors will be Incoloy 908 , a ferromagnetic material developed especially for this purpose to survive the $\mathrm{Nb}_{3} \mathrm{Sn}$ reaction conditions and to match the thermal contraction of the superconducting composite [3]. The $\mathrm{Nb}-\mathrm{Ti}$ superconductor will be sheathed with 316LN material, an austenitic stainless steel alloy well suited for cryogenic applications [4].

\section{SUPERCONDUCTOR DESIGN CRITERIA}

Table 1 below lists the more relevant superconductor design criteria adopted by the TPX project for use in determining design adequacy [5]. In certain cases, the TPX criteria are more aggressive than those adopted by the International Thermonuclear Experimental Reactor (ITER), but we feel our criteria are justified by our experimental results.

Table 1

TPX Conductor Design Criteria

\begin{tabular}{|c|c|}
\hline Parameter & Value \\
\hline $\begin{array}{l}\text { Temperature Margin, } \\
T_{C S}-T_{\text {hath }}\end{array}$ & $>1 \mathrm{~K}$ \\
\hline $\begin{array}{l}\text { Temperature Headroom, } \\
T_{c s}-T_{\text {inlet }}\end{array}$ & $>2 \mathrm{~K}$ \\
\hline $\begin{array}{l}\text { Energy Margin, } \\
\mathbf{H}_{\text {cable(Tcs) }}-\mathbf{H}_{\text {cable(Thath) }}\end{array}$ & $>300 \mathrm{~mJ} / \mathrm{cc}$ \\
\hline $\begin{array}{l}\text { Energy Headroom, } \\
\mathrm{H}_{\text {cable(Tcs) }}-\mathrm{H}_{\text {cable(Tinlet) }}\end{array}$ & $>600 \mathrm{~mJ} / \mathrm{cc}$ \\
\hline $\begin{array}{l}\text { Energy Headroom Safety Factor, } \\
\text { Energy Deposited / Energy Headroom }\end{array}$ & $>2$ \\
\hline Fraction of Critical Current & $<0.6$ \\
\hline Cable Space Helium Fraction & $35 \%$ to $45 \%$ \\
\hline $\begin{array}{l}\text { Recovery Power Balance, W/m }{ }^{2}-\mathrm{K} \\
J_{c u}^{2} \rho_{c u} A_{c u} / P_{w}\left(T_{c}-T_{b a t h}\right)\end{array}$ & $\begin{array}{l}<1000 \text { for } \mathrm{Nb} 3 \mathrm{Sn} \\
<600 \text { for } \mathrm{Nb}-\mathrm{Ti}\end{array}$ \\
\hline
\end{tabular}

\section{CONDUCTOR DESIGN}

The conductor designs shown in Fig. 1- 3 reflect the design state at the time of the magnet system Preliminary Design Review which was held in September, 1995.

A rather unique feature of the TPX conductors is the incorporation of internal quench detection sensors directly in 
the cable. Two types of quench detection sensors are under consideration: coaxial wire voltage sensors and fiber optic temperature sensors. Further information on this aspect can be found in several other papers presented at this conference [6-9]. Recent experimental results suggest that the best location for the voltage sensors is in the center of the next-tolast cabling stage.

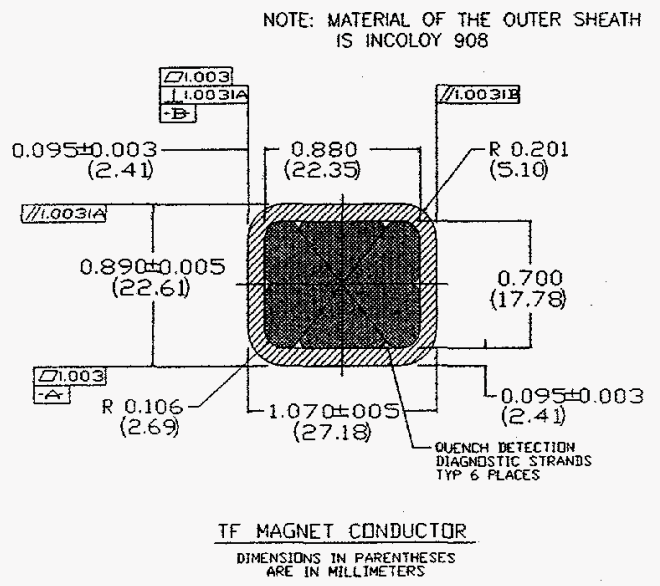

Fig. 1 TPX TF Conductor

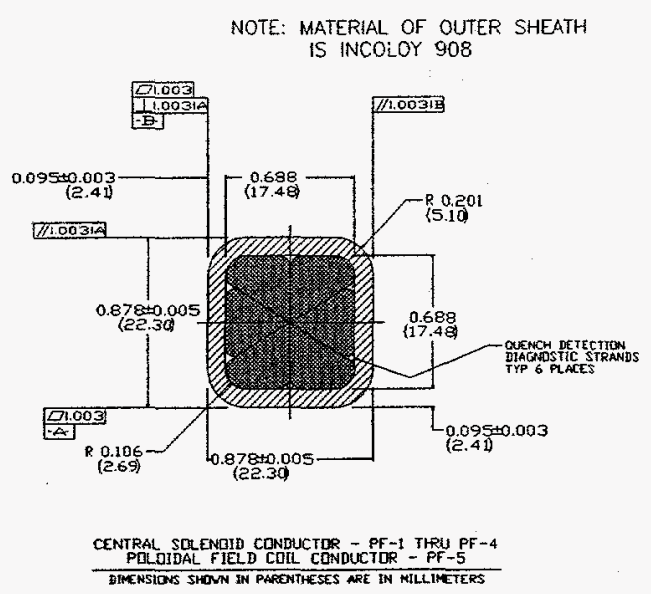

Fig. 2 TPX CS \& PF-5 Conductor

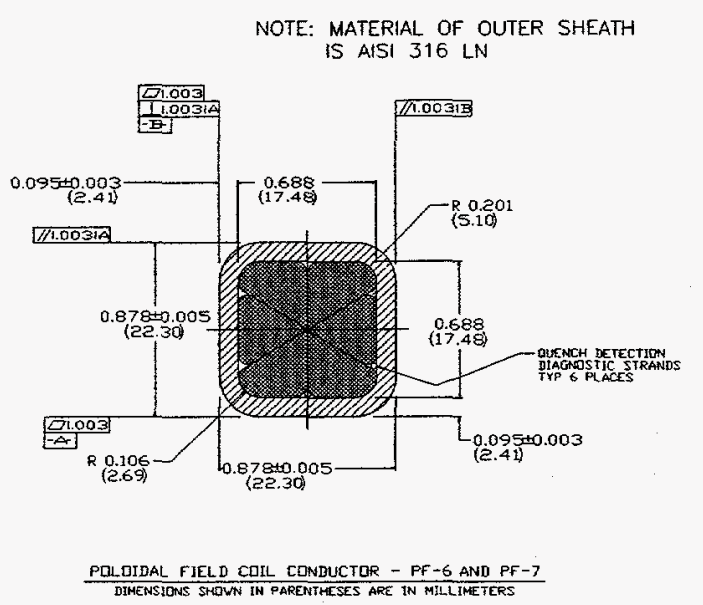

Fig. 3 TPX PF-6 \& PF-7 Conductor

\section{CONDUCTOR DEVELOPMENT PLAN}

The elements of our overall plan to develop the conductors for TPX is presented below in Fig. 4. The plan is not a standalone plan, but is integrated with other Lab effort in quench detection R\&D and magnet fabrication R\&D which is being done by the magnet subcontractors. The connection to quench detection $R \& D$ is obvious since we need to incorporate sensors in the cable space to obtain the needed signal to noise ratio to allow fast enough detection to protect the coils. The magnet fabrication R\&D generated requirements on material property consistency to allow precision bending and forming over the entire length of conductor, and the studies carried out on the thermal behavior of cross-sectionally full-size winding pack mockups will need to be reconciled with the Vendorproposed time-temperature profiles needed to form the $\mathrm{Nb}_{3} \mathrm{Sn}$ phase.

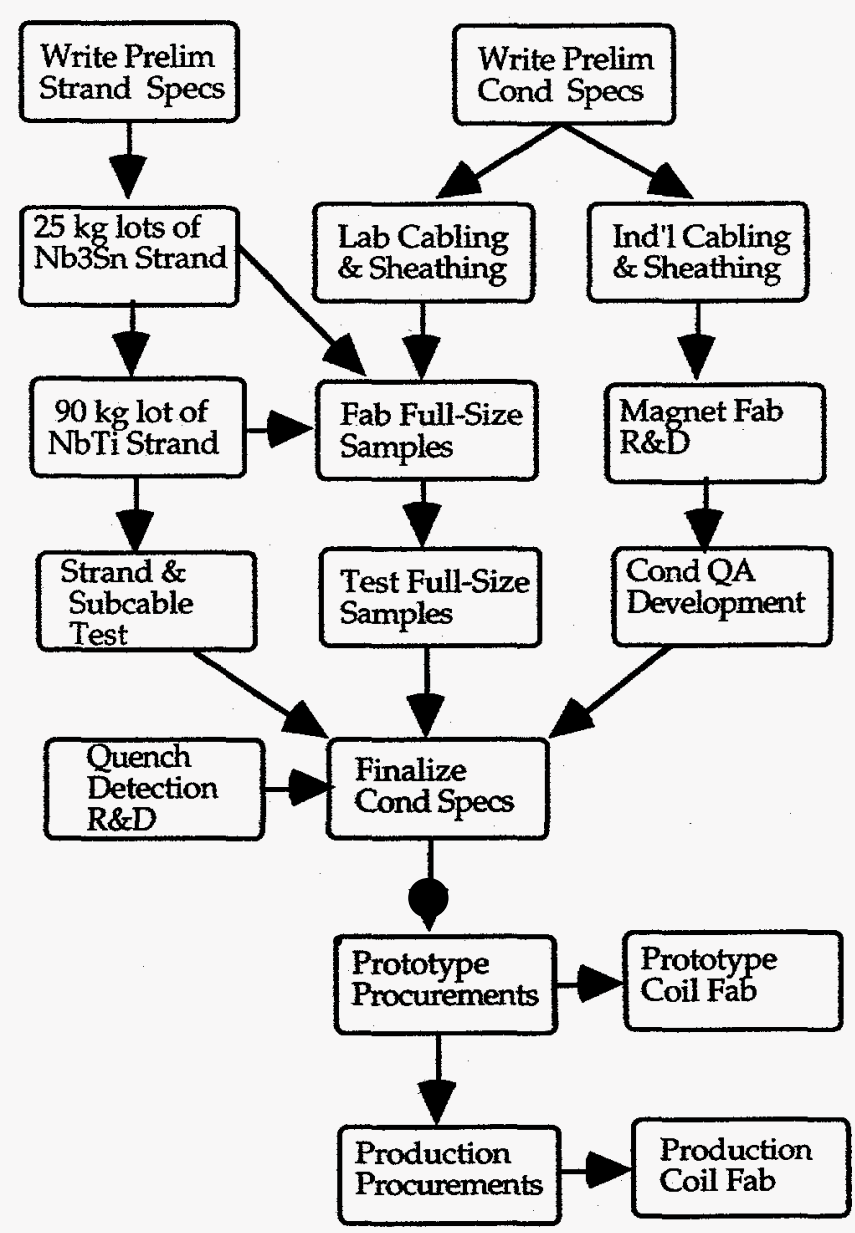

Fig. 4 The TPX Conductor Development Plan

\section{STRAND DEVELOPMENT STATUS}

The development of the superconducting strand proceeded as outlined in a paper presented at the previous SOFE conference [10], although the parameters were changed to reflect the changes in the magnet design. Also, we only purchased $90 \mathrm{~kg}$ 
of $\mathrm{Nb}-\mathrm{Ti}$ vs the $250 \mathrm{~kg}$ lot previously proposed to keep our development costs within budget. Table 2 below presents the parameters of the preliminary strand specifications used to procure multiple $25 \mathrm{~kg}$ lots of $\mathrm{Nb}_{3} \mathrm{Sn}$ strand and the single $90 \mathrm{~kg}$ lot of $\mathrm{Nb}$-Ti strand.

Table 2

TPX Preliminary Strand Requirements

\begin{tabular}{|c|c|c|c|c|}
\hline Parameter & Units & TF & CS/PF-5 & PF-6/PF-7 \\
\hline Conductor Type & & $\mathrm{Nb}_{3} \mathrm{Sn}$ & $\mathrm{Nb}_{3} \mathrm{Sn}$ & $\mathrm{Nb}-\mathrm{Ti}$ \\
\hline $\mathrm{E}_{\mathrm{c}} @ 4.2 \mathrm{~K}, 10 \mu \mathrm{V} / \mathrm{m}$ & A & 148 & 138 & 550 \\
\hline Field to Measure $I_{c}$ & $\mathrm{~T}$ & 9 & 8 & 5 \\
\hline A value & & $>20$ & $\geq 20$ & $>20$ \\
\hline Diameter & $\mathrm{mm}$ & $0.78 \pm 0.01$ & $0.78 \pm 0.01$ & $0.78 \pm 0.01$ \\
\hline Copper : noncopper ratio & & $2.5 \pm .2$ & $3.5 \pm .2$ & $2.5 \pm .2$ \\
\hline Cr plating thickness & $\mu \mathrm{m}$ & $1 \pm .5$ & $1 \pm .5$ & $1 \pm .5$ \\
\hline Final RRR & & $>75$ & $>75$ & $>150$ \\
\hline Twist Pitch, Right Hand ${ }^{(a)}$ & $\mathrm{mm}$ & $9 \pm 1$ & $<10$ & $9 \pm 1$ \\
\hline Hysteresis loss, $\pm 3 \mathrm{~T}$ & $\begin{array}{c}\mathrm{mJ} / \mathrm{cc} \\
\text { (noncopper } \\
\text { vol.) }\end{array}$ & $<550$ & $<550$ & $<150$ \\
\hline Piece Length & $\mathrm{m}$ & $>1500$ & $>1100$ & $>3300$ \\
\hline
\end{tabular}

Note: (a) In follow-on specifications this will be changed to $12 \pm 1 \mathrm{~mm}$.

The strand development program was very successful, since two vendors were able to produce strand fully compliant with both $\mathrm{Nb}_{3} \mathrm{Sn}$ specifications and our single $\mathrm{Nb}-\mathrm{Ti}$ vendor met the $\mathrm{Nb}-\mathrm{Ti}$ specifications. Both of the $\mathrm{Nb}_{3} \mathrm{Sn}$ compliant materials were made using the internal tin approach. One bronze-route strand came within $80 \%$ of the critical current specification, and had some trouble in meeting the piece length requirement. The conjecture was that the critical current specification might be met by a billet redesign and a longer twist pitch could solve the piece length problem, but there was no time or funds to pursue this. On the $\mathrm{Nb}-\mathrm{Ti}$ front, the vendor did have some initial piece length problems, but they were eventually overcome by finding a suitable thermomechanical sequencing. Lengthening the twist pitch to $12 \mathrm{~mm}$ from the specified $9 \mathrm{~mm}$ would probably lessen the probability of strand breakage during processing.

\section{STRAND \& SUBCABLE TESTS}

A limited amount of strand testing to supplement the vendorsupplied data was carried out by MIT, and the measurements supported the vendor data. At least two interesting phenomena have been discovered in the course of carrying out the tests beyond the conventional tests to confirm the vendor data. The first is that the critical current increases upon successive cooldowns and retests, which suggests that the residual compressive strain decreases upon repeated cooldowns [11-12]. To the best of our knowledge, this has not been observed before and may be related to the large volume of copper stabilizer incorporated in the TPX $\mathrm{Nb}_{3} \mathrm{Sn}$ strand. The second interesting observation is an apparent connection between heat treatment conditions and the peak compressive prestrain. Measurements of prestrain on two samples of 3.5:1 strand from one vendor exhibited significantly different levels of prestrain, i.e., $0.42 \%$ vs. $0.30 \%$ [13]. The only apparent difference in these 2 specimens was the heat treatment conditions; the sample with the higher prestrain was ramped to $660 \mathrm{C}$ in a stepwise fashion (average rate of $60 \mathrm{C}$ /hour) and then furnace cooled after 240 hours at $660 \mathrm{C}$, whereas the other sample was continuously ramped at $60 \mathrm{C}$ hour to $660 \mathrm{C}$ and then cooled at $50 \mathrm{C} /$ hour to $400 \mathrm{C}$. It appears that the latter heat treatment allows for some relaxation to take place, probably by creep of the copper stabilizer [14]. More work needs to be done in order to understand these effects.

A series of $\mathrm{dc}$ and pulse tests were performed on cables consisting of 27 strands (18 CS Nb3 3 nn strands and 9 OFHC copper strands) simulating the CS conductor [15-16]. In contrast to earlier experiments using US-DPC material, no ramp rate limitations or quenches were observed for conditions simulating TPX charge/discharge requirements. The subcable critical current values were slightly lower than predicted from the single strand measurements, and there was some further degradation upon ramping, but these values were difficult to determine experimentally so further work would be needed to accurately quantify this. High-current quenches were obtained by setting the sample current and ramping the background field; the values of power balance for these quenches lends support to the suitability of the TPX power balance criterion of $1000 \mathrm{~W} / \mathrm{m}^{2}-\mathrm{K}$.

\section{FULL-SIZE CONDUCTOR TESTS}

Work is in progress on fabrication and testing of full-size conductors to verify the conductor design assumptions as early as possible. Three 3.5-m-long TF-type conductors have been produced by LLNL personnel on the LBL cabling machine. One of these conductors is made from sub-specification $\mathrm{Nb}_{3} \mathrm{Sn}$ strand and sheathed with $316 \mathrm{LN}$. This is a practice piece that is used to checkout the various steps in the sample production process to eliminate problems in making the real test samples. The "real" samples have Incoloy 908 conduits; one sample features 486 strands of 2.5:1 TF strand, cabled in a $3 \times 3 \times 3 \times 3 \times 6$ pattern the other is a hybrid cable of 486 strands, in which one strand in each starting triplet is OFHC copper and the other two are 1.8:1 TF strand. This allows us to assess two cable configurations in one test since the actual test article consists of one leg of each type, connected at the lower end by a 0.5 -m-long joint.

The samples will be heat treated in a newly-acquired tube furnace at LLNL. A major concern is the elimination of cracking in the Incoloy 908 conduit due to grain boundary oxidation; we plan to overcome this problem by performing the heat treatment with the open-ended sample under vacuum 
in a retort; we have verified this process on small and large scale tests.

The conductor tests will be performed in a Pulse Test Facility (PTF) now under construction at MIT. The facility will provide a $8.4 \mathrm{~T}$ peak transverse field with a flat top of about $30 \mathrm{sec}$. We plan to provide copper coils which will provide a pulsed longitudinal field while the transverse field is applied. In this facility the TPX operational conditions can be simulated, giving us experimental verification of the TPX conductor design.

\section{INDUSTRIAL CABLING AND SHEATHING}

We are carrying out a considerable industrial effort in conductor manufacturing. Although we had assumed at the outset of the program that the sheath would be formed by welding strip around the cable in a continuous process, we allowed proposals to be submitted using other processes. The winning proposal in our competitive procurement process is based on a process in which the cable is inserted into sections of tubing, and the lengths of tubing are joined by orbital butt welding. The tubing is formed around the cable by die drawing with a large diameter bullblock and spooled onto a large diameter spool. The cable, included in this contract, is made from OFHC strand, some of which is Cr plated, and includes co-wound stainless steel wires as dummy quench detection sensors and was intended to mimic the TPX cable specification which was in work at the time this contract was placed.

Work is presently underway to produce TF-type demonstration conductor; $200 \mathrm{~m}$ of tubes were loaded with cable and the welding/drawing/spooling operations were underway. After the $200 \mathrm{~m}$ of TF-style demonstration conductor are completed, the machine will be used to produce $500 \mathrm{~m}$ of CS-style conductor. Based on the development tests that have been carried out, we are confident that this method will be capable of producing reliable CICC since the amount of welding required is much less than the conventional tube mill approach and the non-continuous production method allows for the development of sensitive QA inspection techniques with the possibility of repair before the conduit is formed around the cable.

\section{ACKNOWLEDGMENTS}

The authors would like to acknowledge the efforts of K. I, Thomassen, J. Sinnis, and J. Schmidt (TPX Project Office), S. Shen, J. Parker, R. Jenkins, and A. Horner at LLNL, R. Scanlan and H. Higley at LBL, and our Vendors, Everson Electric Co., Intermagnetics General Corp., Oxford Superconductors, Supercon, and Teledyne Wah Chang.

This work was performed under the auspices of the U.S. Department of Energy by Lawrence Livermore National Laboratory under contract number W-7405-ENG-48, and by
Princeton Plasma Physics Laboratory under contract number DE-AC02-76-CH03073.

\section{REFERENCES}

[1] G. A. Deis, et al., "TPX Superconducting Tokamak Magnet System 1995 Design and Status Overview," 16th IEEE/NPSS Symposium on Fusion Engineering, September 30 - October 5, 1995, in press.

[2] H. Calvin, et al., "TPX Superconducting PF Magnets," 16th IEEE/NPSS Symposium on Fusion Engineering, September 30 - October 5, 1995, in press.

[3] I. S. Hwang, R. G. Ballinger, M. M. Morra, and M. M. Steeves, in "Advances in Cryogenic Engineering (Materials)," Vol. 38, F. R. Fickett and R. P. Reed, eds., Plenum Press, New York, 1992, p. 1.

[4] R. P. Reed and A. F. Clark, eds., "Materials at Low Temperatures," ISBN: $0-87170-146-4$, p. 378 .

[5] I. Zatz and P. Bonanos, "TPX Structural and Cryogenic Design Criteria", TPX Doc \# 94-950117-PPPL-IZatz-01.

[6] P. W. Wang, et al., "Numerical Modeling of the Voltage Sensors for Quench Detection in the TPX TF and PF Conductors," 16th IEEE/NPSS Symposium on Fusion Engineering, September 30 - October S, 1995, in press.

[7] M. R. Chaplin, et al., "Co-Wound Voltage Sensor R\&D for TPX Magnets," 16th IEEE/NPSS Symposium on Fusion Engineering, September 30 - October 5, 1995, in press.

[8] S. P. Smith and S. Pourrahimi, "A Fiberoptic Quench Detection System for Cable-In-Conduit Magnets," 16th IEEE/NPSS Symposium on Fusion Engineering, September 30 - October 5, 1995, in press.

[9] M. R. Chaplin, et al., "Local I\&C for the TPX TF and PF Magnets," 16th IEEE/NPSS Symposium on Fusion Engineering, September 30 - October 5 , 1995, in press.

[10] J. P. Zbasnik, et al., "The TPX Magnet R\&D Program," proc. 15th IEEE/NPSS Symposium on Fusion Engineering, October 11-15, 1993, p. 794.

[11] M. Takayasu, "TPX IGC Wire Test Result Summary: Hysteresis Loss, RRR, and Critical Currents," TPX Doc. \# 14-950914-MTT-MTakayasu-01.

[12] P. Michael, "Correlation Fit for IGC-TPX-PF Wire, Rev. 1," TPX Doc. \# 14-950913-MIT-PMichael-03.

[13] J. Ekin, September 12, 1995 letter to M Takayasu.

[14] J. Ekin, private communication.

[15] S. Jeong, et al., "Ramp-rate Limitation Experiments and Analysis in Support of the TPX Magnets," 16th IEEE/NPSS Symposium on Fusion Engineering, September 30 - October 5, 1995, in press.

[16] J. H. Schultz and S. Jeong, "Interpretation of Ramp-Rate Limitation Experiments on IGC 3.5:1 Copper/Noncopper Hybrid Subcable," MIT Memo ITER/US/EV-MAG/J.Schultz/9.28/1. 